\title{
Accommodation Space Transformation System in Faulted Basin
}

\author{
Zaixing Jiang ${ }^{*}, \mathrm{a}$, Yingchang Cao ${ }^{\mathrm{b}}$, Weili Yang $^{\mathrm{c}}$, Tong Wang ${ }^{\mathrm{a}}$ and Le Zhang ${ }^{\mathrm{d}}$ \\ ${ }^{a}$ College of Energy, China University of Geosciences, Beijing, China \\ ${ }^{b}$ College of Geo-Resources and Information, China University of Petroleum, Dongying, China \\ ${ }^{c}$ Research Institute of Petroleum Exploration \& Production, Sinopec, China \\ ${ }^{d}$ Subsurface Well Planning Department, Beijing Office, ConocoPhillips China Inc., China
}

\begin{abstract}
The variation of accommodation space in faulted basin is mainly affected by three factors: the differential subsidence of basement, the deposition of sediments and the variation of absolute lake level. In this article, the variation laws of accommodation space have been analyzed and its distribution characteristics have been explained when the lake level is descending, still and ascending and the deposition and subsidence are taken into account. And at the same time, the existence conditions of transformational belt and its planimetric positions can be figured out with analyses above. Accommodation space changes both through time and basin, as a see-saw movement, which is called accommodation space transformation. The characteristics of accommodation space and its products constitute the accommodation transformation system. Transformation surface and body are basic elements of the accommodation transformation system. The accommodation transformation system can be divided into several grades according to originating mechanism and product characteristics. It is considered that formations in different grades of transformation system have different features of sand body and hydrocarbon potential.
\end{abstract}

Keywords: Accommodation space, faulted basin, transformation, sea(lake)level, oil and gas.

\section{INTRODUCTION}

The accommodation space is a conception about the base level which was firstly proposed by Jervey in 1988. It is the potential space for the sediment to deposit and it should be under the base level (if above, erosion will occur). The accommodation space includes the old space, which has not been filled in early period and new space, which is formed in the process of the sedimentation [1-3].

The concept of sequence stratigraphy has been established by studies conducted mainly on marine passive continental margins. This emphasizes conception the consistency and cyclicity of sea (lake) level and was widely used in both marine and nonmarine environment [4-8]. Suess in 1906 firstly proposed the globality of the sea level variation [9, 10]. In 1977, according to the study on seismic stratigraphy at different continental margins in whole world, Vail drew conclusions that the variation of global sea level has the characteristics of isochronism and cyclicity, and their variation amplitudes are similar. According to this research, the global cyclic variation chart has been accomplished and the foundation of the sequence stratigraphy has been laid $[9,11]$. With reference to the study, conducted on the magnetic stratigraphy, biostratigraphy and chronostratigraphy in 1987, Haq made the global sea level variation curve from Triassic to now precisely. Because of the correlative characteristic of the sequence stratigraphic boundary in global or between basins, it has got widespread use in geological research field [9]. Posamentier was one of the only few persons who have modified the consistency of the relative sea level variation.

*Address correspondence to this author at the College of Energy, China University of Geosciences, Beijing, China; E-mail: jiangzx@cugb.edu.cn
He has studied the marine passive continental margins at first and considered that there exists a balance point, which has been defined as the point where the global sea level variation speed equaled to the subsidence speed vertically [4, 12]. Taken this point as a boundary, the continental shelf can be divided into two parts. On the seaward direction, the subsidence speed is larger than descending speed of the global sea level, and as a result, the accommodation space increased. On the shoreward direction, the accommodation space decreases because the subsidence speed is less than descending speed of the global sea level. This point can be a critical point which can divide the continental shelf into two parts. One is relative sea level ascending belt and the other is descending belt. After that, in 1993, Posamentier and Allen put forward a sequence stratigraphy model based on foreland collision basin. In the foreland basin, due to the imbalance of the extrusion and thrust, there are some zoning phenomena and there also exists a balance point at which the tectonic subsidence speed equals to the descending speed of the sea level where the relative sea level remains still. In the area close to the folding and thrusting belt, the subsidence speed is larger than the descending speed of the sea level and as a result, the relative sea level ascends. In the far area, on the contrary, the relative sea level descends and as a result, unconformity comes into being $[13,14]$. But, in these two situations described above, the relationship among the imbalance and the sedimentary records and sequence stratigraphy has not been pointed out.

In lake basins, according to the position of the lake level, Chi (1998) classified the accommodation space into two types. Between the depositional base level and the lake level is accommodation space I and between the lake level and the base surface of the lake basin is the II [15]. Liu (1997) discussed the influences caused by structural titling on the lake 
level change in single-faulted basin [16]. In an ideal condition, the structural titling can cause the lake level descending at the gentle slope and ascending at the steep slope where the accommodation space was increased. When the sedimentation occurred, due to the relationship between the relative lake level ascending caused by the new sediment and relative lake level descending at the initial shoreline, there existed three probabilities at the gentle slope, the ascending, stillness and descending of the lake level. The influence of the sediment on the sequence has been shown by the direction of the sediment source. Due to the variation of the sediment supply and speed, there are some imbalances in relative lake level change under certain conditions. During the study of the Lower Sha Er member in Dongying depression, Zhang (1997) found that in the period from initial increase to rapid increase of the relative lake level, under the situation that the subsidence conditions were the same in the direction of structural line, the progradation of the delta and river would cease and retrogradation would occur. But, due to the sediment supply difference between the east and west, when the sediment supply speed was less than the increasing speed of the accommodation space and the retrogradation occurred in the west, the progradation was still in process because the sediment supply speed was larger than the increasing speed of the accommodation space in the east [17]. In the research of Biyang depression, Hu (1997) put forward that in the faulted basin, the variation of the accommodation space in the whole basin was not consistent due to the imbalance of the lake level change, movement of boundary faults and sediment supply $[18,19]$.

During the study of the accommodation space and lake level in Qinshankou formation in the Songliao basin, Jiang et al. (2005) has put forward the inconsistence of the lake level change in depressed basin and the accommodation space transformation, and therefore, brought forward the concept of accommodation transformation system [20]. In faulted basin, due to the differential subsidence of the basement caused by the structural titling movement, at the outside of the steep and gentle slope, the accommodation space decreases and the relative lake level descends. On the contrary, at the inside of the steep and gentle slope, the accommodation space increases and the relative lake level ascends. Between these two areas, there exists a transformation belt where the accommodation space remains constant. Under this situation, the distribution and transformation of the accommodation space are the researching emphasis of this paper. This study will provide a new methodology for strata correlation and petroleum exploration.

\section{FACTORS AFFECTING THE DISTRIBUTION OF THE ACCOMMODATION SPACE IN FAULTED BASIN}

The variation of underwater accommodation space in faulted basin is mainly affected by three factors. First is the differential subsidence of the basement. The subsidence is controlled by the basin boundary fault. As a result, the closer the distance to the boundary fault, the more the subsidence is, and the more the accommodation space increase is. On the contrary, at the far area away from the fault, the accommodation space increase is relatively small. Second is the deposition of sediments. It can cause the decrease in the accommodation space. Third is the variation of absolute lake level. The ascending or descending of the absolute lake level can also cause the increase or decrease of the accommodation space.

Due to the three factors described above, the variation of accommodation space in faulted basin is inconsistent. At the side where the fault is more active, the increase of the accommodation space caused by the subsidence of the basement is larger, so the increase of the whole accommodation space is larger. On the contrary, at the other side where the fault is less active, the increase is smaller. And under certain situations, the accommodation space even can decrease. Therefore, it is possible for existing a balance point (belt) where the accommodation space does not change. This point (belt) is called accommodation space transformation point (belt).

Now, the tilted block will be taken as an example to describe the distributive features of the accommodation space in faulted basin, the conditions for the existing of the accommodation space transformation belt and the way to conform its position.

\section{THE CHARACTERISTICS OF THE ACCOMMODA- TION TRANSFORMATION}

According to the condition described below, the formation has changed position through $\boldsymbol{t}$ period (Fig. 1).

As the $\boldsymbol{V}_{\boldsymbol{h}}$ is a vector, when $\boldsymbol{V}_{\boldsymbol{h}}>\boldsymbol{0}$, the lake level descends and the accommodation space decreases; when $\boldsymbol{V}_{\boldsymbol{h}}<\boldsymbol{0}$, the lake level ascends and the accommodation space increases; when $\boldsymbol{V}_{\boldsymbol{h}}=\mathbf{0}$, the lake level remains still and has no influence on the accommodation space variation.

The accommodation space variation quantity is:

$$
\begin{gathered}
\delta \boldsymbol{h}=\boldsymbol{C}-\boldsymbol{A}-\boldsymbol{B} \ldots \\
\text { 1) When } \boldsymbol{C}_{\max } \leq \boldsymbol{A}+\boldsymbol{B}
\end{gathered}
$$

The lake level descent and the sediment deposition both can decrease the accommodation space, and the decreasing quantity is larger than the accommodation space increase quantity caused by the basement subsidence. As a result, the overall accommodation space decreases, and therefore, exposure or erosion of the sediment occurs and uncomformity comes into being.

\section{2) When $\boldsymbol{C}_{\min } \underline{ } \underline{\boldsymbol{A}+\boldsymbol{B}}$}

The whole decrease quantity of the accommodation space is smaller than the increase quantity caused by the basement subsidence and therefore, the overall accommodation space increases. As a result, the water depth increases and transgression occurs.

\section{3) When $\mathrm{C}_{\underline{\min }}<\mathrm{A}+\mathrm{B}<\mathrm{C}_{\underline{\max }}$}

Since the decrease quantity of the accommodation space caused by the lake level descent and sediment deposition is between the maximum and minimum value of the increase quantity caused by the basement subsidence, there must be a certain point where the equation below is reasonable.

$$
\delta \boldsymbol{h}=\boldsymbol{C}-\boldsymbol{A}-\boldsymbol{B}=\boldsymbol{0} \ldots
$$

It means that the accommodation space at this point remains unchanged. This point is so called accommodation space transformation point. At the left of the point, the ac- 


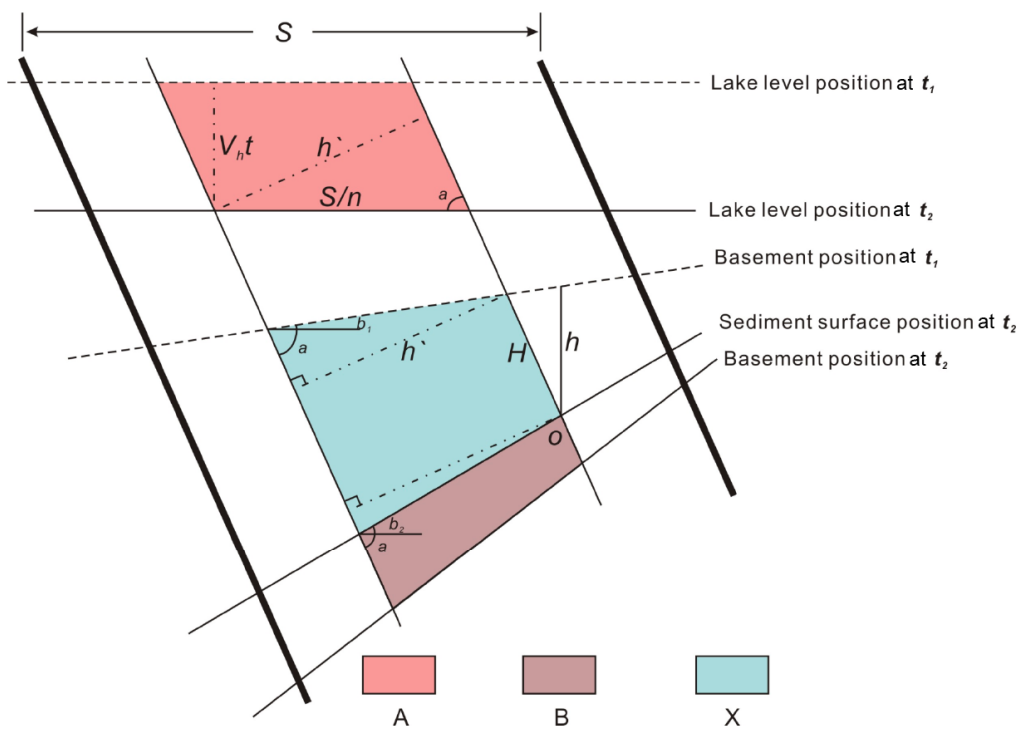

Fig. (1). Analysis diagram on all factors of the accommodation space variation. A: the decrease in accommodation space caused by lake level descending; B: the decrease in accommodation space caused by the sediment deposition; $\mathbf{X}$ : the increase in accommodation space above the sediment surface caused by the basement subsidence at t 2 . $\boldsymbol{V}_{\boldsymbol{h}}$ : the variation speed of the lake level(plus for descending and minus for ascending); $\boldsymbol{t}$ : the geological time from $t_{1}$ to $t_{2} ; \boldsymbol{S}$ : horizontal distance between two faults; $\boldsymbol{a}$ : the angle between the fault and the horizontal line; $\boldsymbol{b}_{\boldsymbol{1}}$ : the angle between the formation and the horizontal line at $t_{1}$ time; $\boldsymbol{b}_{2}$ : the angle between the formation and the horizontal line at $t_{2}$ time; It is assumed that the decrease quantity of the accommodation space caused by the lake level descent is $\boldsymbol{A}$, the decrease quantity caused by the sediment deposition is $\boldsymbol{B}$ and the increase quantity caused by basement subsidence is $\boldsymbol{C}$.

commodation space increases and at the right, decreases. Therefore, at the position of the point, this equation exists.

$C=A+B \ldots$

In this equation, $\boldsymbol{A}$ is independent,

We assume that:

$C=B+X \ldots$

$X$ is the accommodation space increase above the formation which is caused by the basement subsidence at $\boldsymbol{t}_{2}$ time.

So:

$A=X \ldots$

And:

$A=V_{h} \cdot t \cdot \frac{S}{n} \cdots$

$X=\frac{1}{2}\left(2 H+\frac{h^{\prime}}{\tan \left(a+b_{1}\right)}+\frac{h^{\prime}}{\tan \left(180-a-b_{2}\right)}\right) \cdot h^{\prime} \cdots$

$\boldsymbol{h}^{\prime}$ is the vertical distance between two faults, so:

$h^{\prime}=\frac{S}{n} \cdot \sin a \cdots$ $n \rightarrow \infty$

In the above equation, $\boldsymbol{n}$ is the dividing number and

Since $\boldsymbol{h}$ is the vertical distance from $\boldsymbol{t}_{\boldsymbol{1}}$ formation to $\boldsymbol{t}_{2}$ formation, the bottom point of the $\boldsymbol{h}$ is the location of the accommodation space transformation point " $\boldsymbol{O}$ ".

From the trigonometric function:

$\frac{h}{\sin \left(a+b_{1}\right)}=\frac{H}{\sin \left(90+b_{1}\right)} \ldots$

From the former equation:
$V_{h} \cdot t \cdot \frac{S}{n}=\frac{1}{2}\left(2 H+\frac{h^{\prime}}{\tan \left(a+b_{1}\right)}+\frac{h^{\prime}}{\tan \left(180-a-b_{2}\right)}\right) \cdot h^{\prime} \cdots$

And:

$h=f(H) \ldots$

So:

$V_{h} \cdot t \cdot \frac{S}{n}=h^{\prime} \cdot\left(h \cdot \frac{\sin \left(90+b_{1}\right)}{\sin \left(a+b_{1}\right)}+\frac{h^{\prime}}{2 \tan \left(a+b_{1}\right)}\right.$

$\left.+\frac{h^{\prime}}{2 \tan \left(180-a-b_{2}\right)}\right) \cdots$

Also:

$h^{\prime}=\frac{S}{n} \cdot \sin a \ldots$

So:

$$
\begin{aligned}
& V_{h} \cdot t \cdot \frac{S}{n}=\frac{S}{n} \cdot \sin a \cdot\left(h \cdot \frac{\sin \left(90+b_{1}\right)}{\sin \left(a+b_{1}\right)}\right. \\
& \left.+\frac{\frac{\mathrm{S}}{\mathrm{n}} \cdot \operatorname{sina}}{2 \tan \left(\mathrm{a}+\mathrm{b}_{1}\right)}+\frac{\frac{\mathrm{S}}{\mathrm{n}} \cdot \operatorname{sina}}{2 \tan \left(180-\mathrm{a}-\mathrm{b}_{2}\right)}\right) \ldots
\end{aligned}
$$

At last:

$$
\begin{aligned}
& h=\frac{\sin \left(a+b_{1}\right)}{\sin \left(90+b_{1}\right) \cdot \sin a} \cdot\left(V_{h} \cdot t-\frac{S \cdot \sin ^{2} a}{2 \cdot n \cdot \tan \left(a+b_{1}\right)}\right. \\
& \left.-\frac{S \cdot \sin ^{2} a}{2 \cdot n \cdot \tan \left(180-a-b_{2}\right)}\right) \ldots
\end{aligned}
$$


The geological meaning of the above equation is that the accommodation space transformation point locates at the bottom point of the $\boldsymbol{h}$ which is the vertical distance between the $\boldsymbol{t}_{\boldsymbol{1}}$ formation and $\boldsymbol{t}_{2}$ formation. At this specific time, the accommodation space distribution characteristic is shown in Fig. (2).

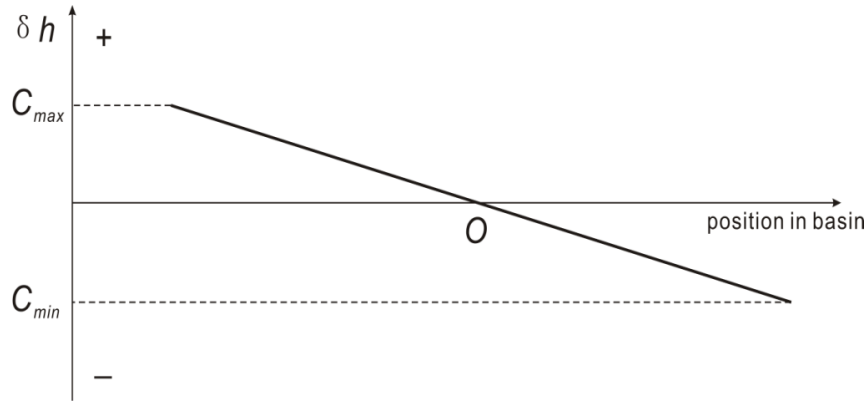

Fig. (2). Diagram of accommodation space distribution characteristic.

\section{ACCOMMODATION TRANSFORMATION SYSTEM}

\section{The Transformation System}

Based on the above analysis, it can be concluded that in the faulted basin, during the episodic movement of the boundary fault, there must be a point, on one side of which the accommodation space increases and the other side, decreases. The point where the accommodation space on this point remains unchanged is the so-called transformation point.

In fact, the geological transformation processes occurred in the geological history are all accompanied by the accommodation space transformation, such as the transformation between the mountain and basin, the faulted basin and depressed basin, the ocean and the continent etc. The characteristics of the accommodation space distribution and combination caused by the transformation, combined with its products, form the accommodation transformation system.

The existence of the transformation means the existence of the inconsistency which shows that the foundation of the traditional sequence stratigraphic research has some limitations. Therefore, the concept of the accommodation transformation system has been put forward to resolve the inconsistent problem caused by the accommodation space transformation process.

\section{The Composition of the Transformation System}

Transformation surface and body are the basic elements of the transformation system.

The transformation surface is the boundary surface across which the accommodation space property hase changed, for example, the surface between the increasing, decreasing or invariable property of the accommodation space.

The transformation body is the sedimentation body confined by two transformation surfaces at the top and bottom. According to the variation of the accommodation space, it can be divided into three types, the accommodation increase body, decrease body and invariable body (Fig. 3). Increase body is the sedimentation body formed under the condition where the accommodation space increases consecutively in a certain period (Fig. 3a). Invariable body is the sedimentation body formed under the condition where the accommodation space remains unchanged in a certain period (Fig. 3b). Decrease body is the sedimentation body formed under the condition where the accommodation space decreases consecutively in a certain period (Fig. 3c).

In the transformation period, according to the consistent or inconsistent variation of the transformation body, it can be divided as unified transformation body and ununified transformation body.

Unified transformation body: in the transformation period, the transformation body has unified variation dimensionally in whole basin. It includes unified increase transformation body, unified decrease transformation body and unified invariable transformation body.

Unified increase transformation body: in a certain period, the accommodation space of one transformation body has unified increase, or composed by increase transformation bodies entirely (Fig. 4a). Its condition is:

\section{$C>A+B$}

Unified invariable transformation body: in a certain period, the accommodation space of one transformation body has no change wholly, or composed by invariable transformation bodies entirely (Fig. $\mathbf{4 b}$ ). Its condition is:

$C=A+B$

Unified decrease transformation body: in a certain period, the accommodation space of one transformation body has unified decreased, or composed by decrease transformation bodies entirely (Fig. $\mathbf{4 c}$ ). Its condition is:

\section{$\boldsymbol{C}<\boldsymbol{A}+\boldsymbol{B}$}

Ununified transformation body: in a certain period, the accommodation space of one transformation body has inconsistent variation (Fig. 4d).

The position where the accommodation space increases and $\boldsymbol{C}>\boldsymbol{A}+\boldsymbol{B}$ is the increase belt.

The position where the accommodation space decreases and $\boldsymbol{C}<\boldsymbol{A}+\boldsymbol{B}$ is the decrease belt.
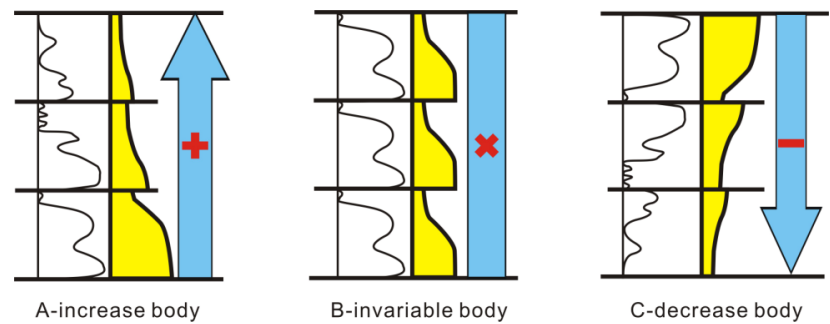

Fig. (3). Types of the transformation body. 

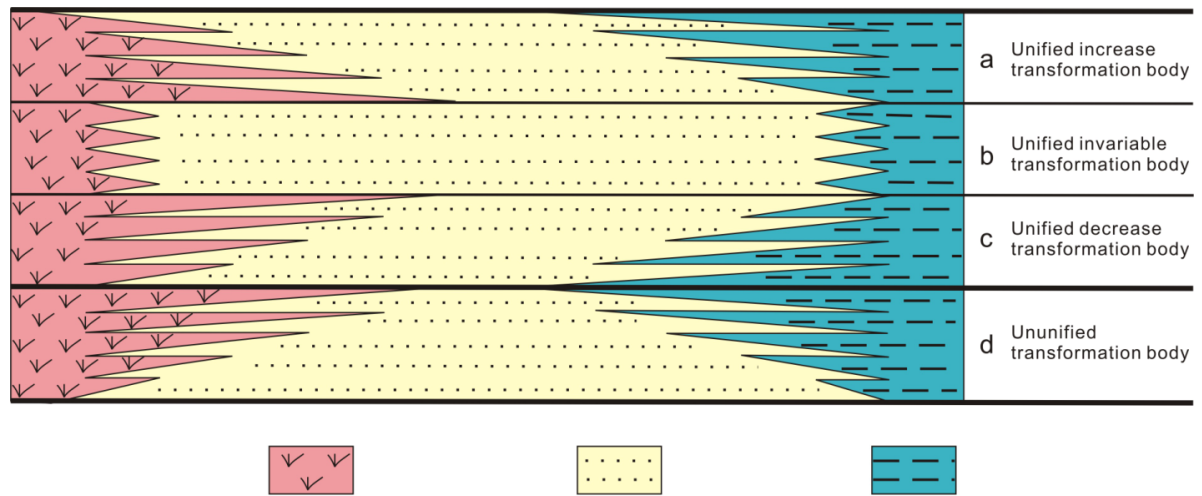

shore lake and delta plain

shallow lake and delta front

deep lake and predelta

Fig. (4). Types of dimensional transformation body.

The position where the accommodation space remains unchanged and $\boldsymbol{C}=\boldsymbol{A}+\boldsymbol{B}$ is the transformation belt.

According to the relation between $\mathrm{A}, \mathrm{B}$ and $\mathrm{C}$, there may exist six kinds of sedimentary distribution patterns in an ununified transformation body, but the pattern shown in Fig. (4d) is more likely to appear in a faulted basin. As it shown, decrease belt developed landward, increase belt basinward and transfomation body between the two.

\section{Grade of the Accommodation Transformation System}

In the faulted basin, there are many phenomena of transformation such as uplift and sedimentary basin, erosion and deposition area, above and below the water, increase and decrease of water depth, and so on. All kinds of transformation described above can be regarded as accommodation space transformation. But different kinds of transformation have different controlling effects on the evolution, deposition, stratigraphic distribution and formation characteristics in a sedimentary basin. According to origination mechanism and product characteristics, accommodation space transformation can be divided into several grades. Accordingly, accommodation transformation system can be divided as Grade I, Grade II and Grade III etc.

Grade I accommodation transformation system mainly includes the sedimentary basin and the uplifts around it. And the Grade I transformation belt is corresponding to the transformation between the basin and the mountain (Fig. 5).
On the plane, Grade I transformation system has three parts annularly distributed (Fig. 6). The outside is the sediment source area, the inside is the sedimentation area and between them is the Grade I transformation belt. This belt is actually an aggregate of many transformation points. In the vertical evolution period of the transformation system, this belt is the transitional area where the source area and basin have alternation.

The Grade II accommodation transformation system is a sub-system of the Grade I and is an evolution result from different period controlled by $2^{\text {nd }}$ level tectonic movement. On the plane or in the vertical, it is corresponding to a sedimentary body or area confined by two neighboring Grade I transformation points. And if the Grade I system is corresponding to the mountain-basin transformation, this scope of Grade II system is corresponding to the sedimentary basin and all the geological processes occurred in the basin. The Grade II transformation system includes more than one transformation points which are the boundaries defining the transformation process between the above-water and belowwater. In fact, this set of points locate at the conjunction area of the lake level and the lakeshore (Fig. 5).

On the plane, Grade II system has also three parts annularly distributed (Fig. 6). The outside is the onshore sedimentary area which is mainly controlled by the fluvial or diluvial facies. The inside is the sedimentary area below water where the continuous lacustrine facies have been formed. Between these two areas is the Grade II transformation belt which is

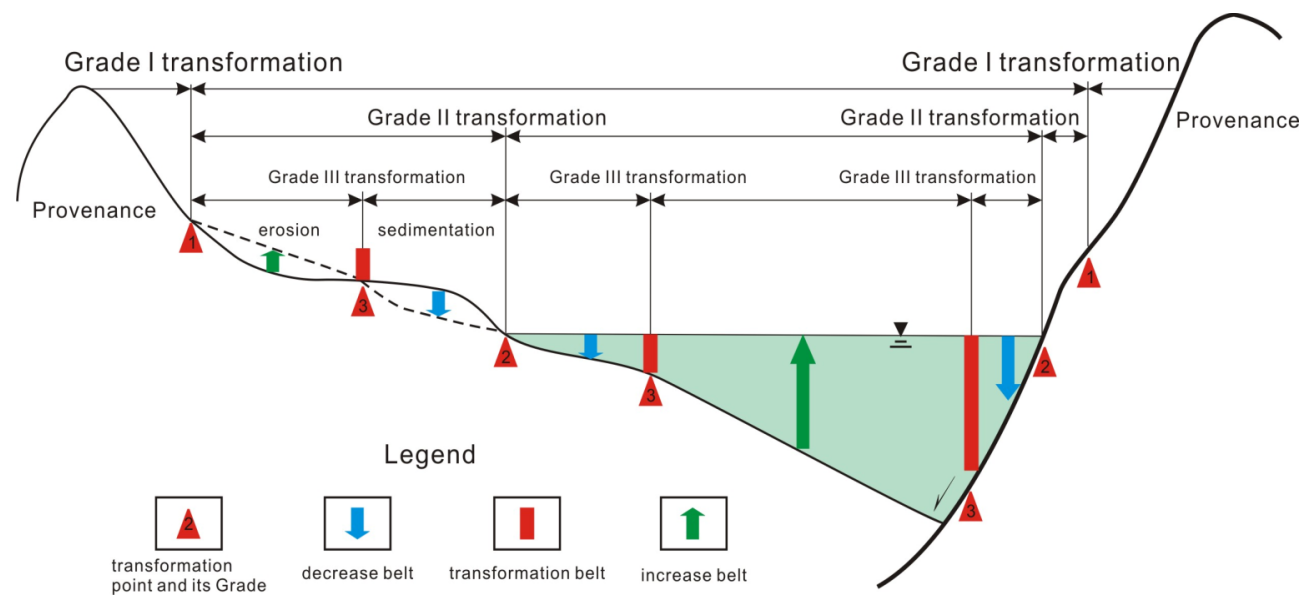

Fig. (5). The Grade of the accommodation transformation system in a single faulted basin. 
actually composed of a series of transformation point. In the aspect of sedimentary combination, the Grade II transformation belt acts as sedimentary alternation between abovewater and below-water which shows the traversing movement of the shoreline.

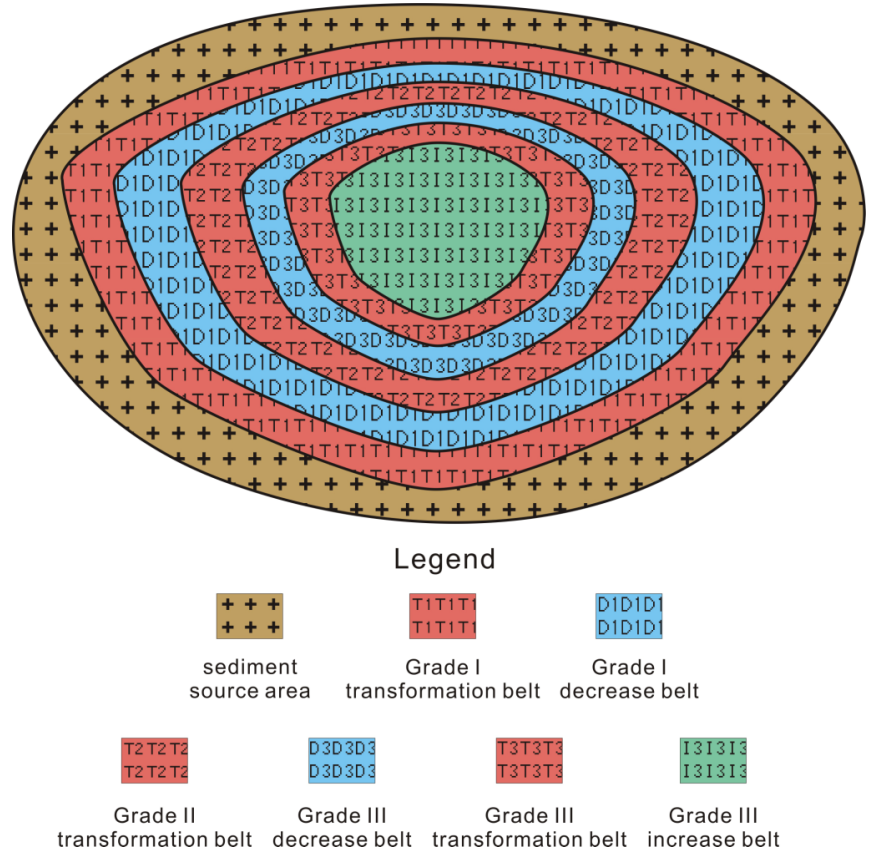

Fig. (6). Plane distribution of accommodation transformation system in an ideal faulted basin.

The Grade III accommodation transformation system is a sub-system of the Grade II and is an evolution result from different period controlled by $3^{\text {rd }}$ level tectonic movement. It is closely related to the episodic tectonic movement which belongs to $2^{\text {nd }}$ cyclic tectonic movement. On the plane or in the vertical, it is corresponding to a sedimentary body or area confined by two neighboring Grade II transformation points. And if the Grade II transformation system is corresponding to a sedimentary basin, the Grade III system is corresponding to the transformation process between the above-water and below-water, in addition to all the geological processes that occurred in it. In the faulted basin, the Grade III system also includes more than one transformation point which can be divided into two types. The one is the point between the areas where the water depth increases and decreases. The other is the point between the areas where the water depth decreases and new accommodation space comes into being.

On the plane, Grade III system can also be divided into three parts which are annularly distributed. The outside is the accommodation space decrease belt. The inside, center of the basin, is the accommodation space increase belt. And the area between them is the Grade III transformation belt which is composed of a series of points where the accommodation space remains unchanged.

\section{RELATIONSHIP BETWEEN ACCOMMODATION SPACE TRANSFORMATION AND HYDROCARBON IN FAULTED BASIN}

In an ideal single faulted basin, on the plane or in the vertical, there exists different levels of transformation and sedimentary zones which are annularly distribution on the plane (Fig. 6). From the basin edge to the center, there or- derly exists the sediment source area, Grade I transformation belt, diluvial area, Grade II transformation belt, accommodation space decrease belt, Grade III transformation belt and accommodation space increase belt. These different zones have different distribution characteristics of sand bodies and hydrocarbon.

\section{Provinence Area}

The provinence area which locates in the outermost of a sedimentary basin supplies sediments for the basin. It is mainly composed of uplifts and mountains where the erosion and denudation are dominant and intermountain canyons are developed by cooperative actions of streams and tectonic movements. With the sedimentary basin being filled and the base level of deposition increasing, Grade I transformation belt moves towards the outside of the basin and the sediment source area gradually reduces and even disappears completely. In addition, the intermountain canyons are also being filled gradually. For example, the intermountain canyons widely developed on Yihezhuang and Chenjiazhuang uplifts in Jiyang depression were mainly formed in the developmental period of the Paleogene transformation system. They were gradually filled during the deposition of the Neocene and had their full fill in the Quaternary. As a result, the sediment source area disappeared [21].

The essential feature of the sediment source area is that it undergoes eluviations and erosions and at the same time supplies clastic material for the basin. If the basement is composed of carbonate rock, it is very easy to form the karst landform, which has plentiful pores and bores, and even large scale of caves under appropriate tectonic movement. Due to these features described above, it is easy to form good reservoir bed in this area. And at the same time, the source and cap rock are the key factors for the accumulation of the oil and gas.

\section{Grade I Transformation Belt and the Diluvial Area}

Grade I transformation belt is the traverse zone of basinmountain transformation and in fact is the conjunction region of erosion and deposition in front of the mountain. For a long time, it is exposed in atmosphere and easy to be weathered and eluviated. If the basement is composed of carbonate rock, reservoir beds with abundant pores and bores are easy to form. With the traverse movement of transformation points, piedmont diluvial facies can deposit above the Grade I transformation belt and as a result, cap rock comes into being. Besides, the deposition of later transformation periods can form cap rocks which is the key factor for the oil and gas accumulation [22] (Fig. 7).

Grade I transformation belt usually locates at the outside of a basin with relatively high structural position. Moreover, the top and bottom boundary of the transformation system, which always equals to regional unconformity, can be perfect migration pathway for oil and gas. But the preservation conditions here are relatively bad, and hydrocarbon reservoirs are easy to be destroyed. Therefore, it is probable to find heavy oil reservoirs here.

\section{Grade II Transformation Belt}

Grade II transformation belt is the above-water and below-water traverse zone. In fact, it is the region where the 


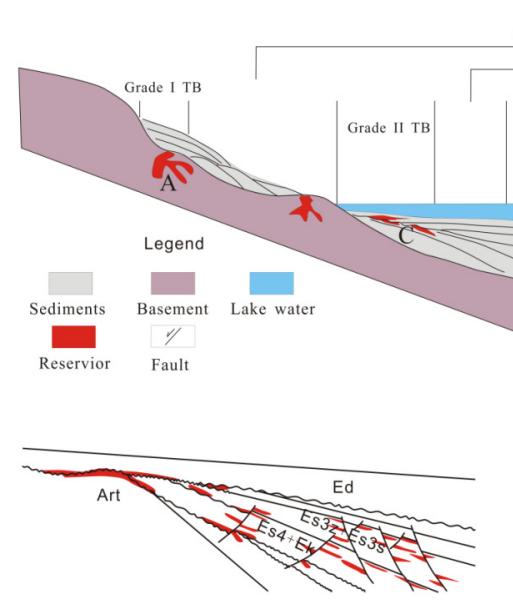

A

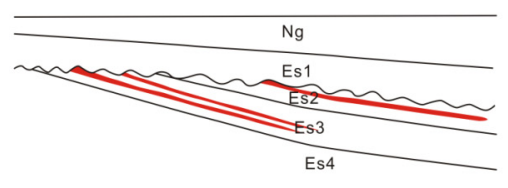

C

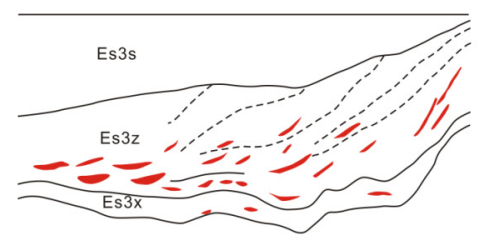

E

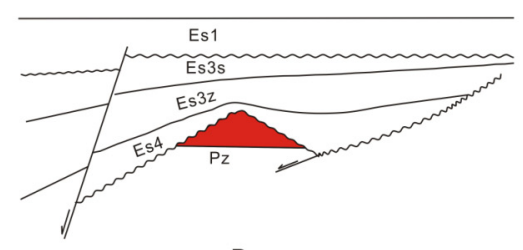

B

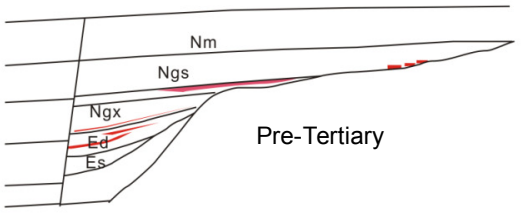

D

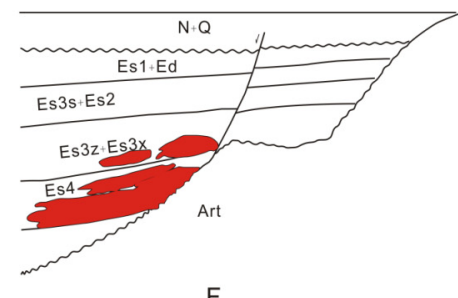

Fig. (7). Relationship between accommodation transformation system and hydrocarbon reservoirs in faulted basin. DB: decrease belt; TB: transformation belt; IB: increase belt. (A) Buried hill pattern controlled by Grade I transformation belt in South Dongying. (B) Reservoir types of buried hill pattern controlled by Grade I transformation belt in Wangzhuang oil field. (C) Stratigraphic reservoirs controlled by Grade II transformation belt in Jinjia oil field. (D) Stratigraphic reservoir types controlled by Grade II transformation belt in Wangzhuang area. (E) Lithologic reservoirs controlled by Grade III transformation belt in Niuzhuang oil field. (F) Reservoir pattern controlled by Grade III transformation belt in Shengtuo area.

shoreline is waggling and the basin rim unconformity is distributed. The main sedimentary facies here are shallow facies, such as fluvial facies, shallow lacustrine facies and delta facies. As a result, sand bodies are well developed in this region.

The width of this belt is usually related with the slope gradient of ancient landform. Generally, the gentler the slope gradient is, the wider this transformation belt is. Therefore, in a faulted basin, it is usually relative wide in gentle slope and relative narrow in steep slope. Therefore, the unconfor-mity surface screened reservoir is easy to be formed here.

\section{Accommodation Space Decrease Belt}

Accommodation space decrease belt is located outside of Grade III transformation system. Its water depth generally decreases during the evolution process. At the gentle slope of the basin, the main sedimentary facies are shallow lacustrine delta, sand sheet and bar. Especially, the delta front is very common. As a result, the sand bodies are well developed.

Although sand bodies are abundant in this region, the conditions of traps, especially nonstructural trap, are not very good.
Only with appropriate structures, structural traps reservoirs can be formed.

\section{Grade III Transformation Belt}

This region is located at the traverse zone for the increase and decrease of the water depth and therefore the gravity flow is easy to be formed. The fluxoturbidite of the delta front can develop on the gentle slope side of the basin and costal underwater fan can develop on the steep slop side. All these lithotomic bodies are always distributed in the mudstone in the deep water and therefore can form good lithologic traps.

\section{Accommodation Space Increase Belt}

Generally, this belt distributes at the basin center, and the water depth keeps increasing continuously. In this belt, mudstone of dark color is well developed and sandstone is relatively rare. Occasionally, there may exist some distal turbidite in the mudstone. The turbidite fan in the delta front is the main type of reservoir bed on the steep slope of the basin. Therefore, the lenticular reservoir in this region is dominant. 
In the concept of accommodation space transformation system, accommodation space changes vertically and horizontally in faulted basin, the change in accommodation space and its products constitute the accommodation space transformation system. This concept acts as a revision to the traditonal sequence stratigraphy. Transformation surface and transformation body are basic elements of the accommodation space transformation system. The transformation body is bounded by transformation surfaces. The accommodation space transformation system provides a new methodology for strata correlation. Different stacking patterns including progradation, retrogradation and aggregation can exist in a chronological unit called "transformation body", this kind of correlation pattern is irreasonable in traditional sequence stratigraphy which emphasizes the consistency of eustasy. Application of accommodation space transformation system depends on the recognition of transformation bodies, which is the base for chronological correlation. But the correlation of transformation bodies is complicated, all the strata stacking patterns recognized can be regarded as different kinds of transformation bodies. Strata patterns reflect the relation between the rate of deposition and the rate of accommodation.

\section{CONCLUSIONS}

(1) In faulted basin, the variation of the accommodation space is mainly affected by the basement subsidence, the sediment deposition and the fluctuation of the lake level. The condition for the existence of the accommodation space transformation is the balance among these three factors.

(2) All the geological processes developed during the geological time are accompanied by accommodation space transformation. According to the mechanism and outcome features of the transformation, the accommodation space transformation can be divided into different grades such as Grade I, II and III.

(3) From the edge to the center, there orderly exist the sediment source area, Grade I transformation belt, diluvial area, Grade II transformation belt, accommodation space decrease belt, Grade III transformation belt and accommodation space increase belt in the faulted basin. Different hydrocarbon reservoirs developed in different zones listed above, which will be a new perspective for oil and gas exploration.

\section{ACKNOWLEDGEMENTS}

Parts of this paper have been presented at the $17^{\text {th }}$ International Sedimentological Conference (Japan, 2006) and received comments and instructions from attendees. We thank the experts of Shengli Oil Field for their support and help during the whole research process. We also thank China National Natural Science Foundation for funding this research project (No.40672078).

\section{REFERENCE}

[1] M. T. Jervey, "Quantitative geological modeling of siliciclastic rock sequence and their seismic expression," In: C.K. Wilgus, B.S. Histings,
C. A. Kendall, et al. Ed. Sea level changes: an integrated approach. SEPM Special Publication 42, pp. 47-69, 1988.

[2] G. H. Browne, B. D. Field, "A review of Cretaceous-Cenozoic sedimentation and tectonic, east coast, South Island, New Zealand," In: D. P. James, D. A. Leckie, Ed. Sequences, Stratigraphy, Sedimentology: Surface and Subsurface. Canad Soc Petrol Geol. Mem vol.15, pp. 3748, 1988.

[3] B. N. Christie, G. S. Mountain, K. G. Miller, "Seismic stratigraphy record of sea-level change," In: R. Revelle, T. P. Barnett, E. J. Barron, et al. Ed. Sea-Level Change. National Academy of Science Studies in Geophysics. Washington DC, pp. 116-40, 1990.

[4] H. W. Posamentier, M. T. Jervey, P. R. Vail, "Eustatic controls on clastic deposition I-conceptual framework," In: C.K. Wilgus, B.S Histings, C. A. Kendall, et al. Ed. Sea level changes: an integrated approach. SEPM Special Publication 42, pp. 109-24, 1988.

[5] J. C. Van Wagoner, H. W. Posamentier, R. M. Mitchum, et al. "An overview of sequence stratigraphy and key definitions," In: C.K. Wilgus, B. S. Histings, C. A. Kendall, et al. Ed. Sea level changes: an integrated approach. SEPM Special Publication 42, pp. 39-45, 1988.

[6] Zaixing Jiang, Huaqi $\mathrm{Li}$, The fundamentals and applications of Sequence stratigraphy, Petroleum Industry Press: Beijing,1995.

[7] Youliang Ji, Shiqi Zhang, The sequence Stratigraphy of terrestrial rift lucustrine basin. Petroleum Industry Press: Beijing,1996.

[8] Youliang Ji, Shiqi Zhang, Fundementals of sequence stratigraphy and the models of forming mechanics of sequence stratigraphy. Geology press: Beijing,1997.

[9] P. R. Vail, R. M. Mitchum, S. Thonpson, "Seicmicstratigraphy and Global changes of sea level," In: C. E. Payton, Ed. Seismicstratigraphyapplication to hydrocarbon exploration. AAPG Memoir 26, pp. 83-97, 1977.

[10] R. Boyd, J. Suter, S. Penland, "Relation of sequence stratigraphy to modern sedimentary environments". Geology, vol. 17, pp. 926-9, Oct 1989.

[11] P. R. Vail, F. Audemard, S. A. Bowman, The stratigraphic signatures of tectonics, eustasy and sedimentology — an overview. Springer Verlag: Berlin, 1991.

[12] H. W. Posamentier, P. R. Vail, "Eustatic controls on clastic deposition II: Sequence and Systems Tract Models". In: C.K. Wilgus, B.S Histings, C. A. Kendall, et al. Ed. Sea level changes: an integrated approach. SEPM Special Publication 42, pp. 126-54, 1988.

[13] H. W. Posamentier, G. T. Allen. "Siliciclastic sequence stratigraphic patterns in foreland ramp - type basins," Geology, vol. 21, pp. 455-8, May 1993.

[14] G. P. Allen, H. W. Posamentier, "Sequence stratigraphy and facies models of an incised valley fill, The Gironde Bay, France," J. Sediment Res, vol. 63, pp. 378-91, 1993.

[15] Yingliu Chi, "Applications of Accommodation Concept to Sequence Studying in a Continential rift basin in case of Paleogene, Bohaiwan Basin," Acta sedimentol. sin, vol.16, pp. 8-13, Dec 1998.

[16] Zhen Liu, Xianbing Zhang, Wanxuan Zhang, "Effect of tectionic tilt of faulted blocks on lake level change of single faulted continental basins," Acta sedimentol. sin, Vol.5, pp. 64-66, Dec 1997.

[17] Ronghong Zhang, Suyu Yu, Jinghua Wang, "The effect of sediments supply condition on sequence stratigraphy analysis in continental lacustrine basins," Earth sci., Vol.22, pp.139-44, Mar 1997.

[18] Shouquan Hu, "Mechanism of allowable space change and its diagram in continental sequence, upper member of He-3, paleogence, Biyang depression," Special oil gas reserv, Vol.5, pp.1-6, Sep 1998.

[19] Shouquan Hu, et al. Study on depositional shoreline break for terrigenous sequence stratigraphy along the steep slope zone of faultdepressed lacustrine basin. J. palaeogeogr.Vol.2, No4, pp131-6.Nov 2000.

[20] Zaixing Jiang, Hongbo Lu, et al. "Transformation of accommodation space of the Cretaceous Qingshankou Formation, the Songliao Basin, NE China," Basin Res, vol. 17, pp. 569-82, Dec 2005.

[21] Zaixing Jiang, Weili Yang, "The lake margin canyon and its hydrocarbon potential," Earth. Sci. Frontr, vol.12, pp. 186-94, Sep 2005.

Pilong $\mathrm{Li}$, "Accumulation models of petroleum and their dynamic characteristics in faulted depression basin," J Univ. Petroleum China, Vol.24, pp.26-8, Aug 2000 